Article

\title{
Public Support Agencies for Innovation in Multilevel Governance Systems: Exploring the Existence of Signs of Complementarity and Substitution
}

\author{
Jennifer González-Blanco ${ }^{1}$, Mercedes Vila-Alonso ${ }^{1}$ and Manuel Guisado-González ${ }^{2, *}$ \\ 1 Faculty of Economics and Business, University of Vigo, Campus Universitario, s/n, 36310 Vigo, Spain; \\ jengonzalez@uvigo.es (J.G.-B.); mvila@uvigo.es (M.V.-A.) \\ 2 Department of Financial Economics and Accounting, University of Extremadura, Av. de la Universidad, s/n, \\ 10071 Cáceres, Spain \\ * Correspondence: manuelguisado@unex.es
}

Received: 24 September 2019; Accepted: 14 October 2019; Published: 18 October 2019

\begin{abstract}
The aim of this paper is to analyze the existence of indications of complementarity/ substitutability between the innovation agencies operating in Spain (regional, national, European, and Seventh Framework Programme), which will allow us to determine the corresponding asymmetries in the implementation of the so-called subsidiarity principle. The data used in the study come from the Panel de Innovación Tecnológica 2015 and 2016 (Spain). The empirical analysis has been carried out by the so-called adoption approach, having previously corrected the selection biases that may be present in the sample. The results obtained indicate that there are indications of substitution between the two Spanish agencies (regional and national), while other relationships between agencies exhibit indications of complementarity. These indications of complementarity/substitutability show that the implementation of the principle of subsidiarity between the two Spanish agencies seem to work correctly, while this implementation is much more diffuse between the two Spanish agencies and the two European agencies. Therefore, these results reveal that there is an obvious asymmetry in the implementation of the principle of subsidiarity between the different agencies. These findings may be an important guide in the decision making of managers. Knowing which agencies are substitutes and which are complementary is extremely relevant information, since it allows the advance determination of which combinations of agencies should be avoided. It also provides policy makers with relevant information for the design of more efficient innovation promotion policies. Finally, this research uses a new methodology for the evaluation of the interaction that takes place between the different public agencies for the promotion of innovation, thus contributing to policy analysts and academics, who conduct such evaluations, have at their disposal a new tool for analysis.
\end{abstract}

Keywords: R\&D subsidies; innovation agencies; adoption approach; complementarity

\section{Introduction}

The economic literature indicates that countries with a greater number of innovative companies are those that generally enjoy greater prosperity and wealth (companies with high profits and consumers with greater purchasing power). It also notes that the productivity and growth of enterprises rely primarily on their respective innovation capabilities [1]. Therefore, public policies that seek to increase the technological capacity of the productive fabric in a particular geographic area (region, country, or economic bloc) contribute to the improvement of welfare policy on that site. Thus, in almost all advanced countries, the respective public administrations promote innovation activities in enterprises or other institutions, through different grant programs and other forms of intervention [2]. However, in Europe, programs that promote entrepreneurship are often too bureaucratized [3]. Thus, in some 
cases, the selection process of companies benefiting from these programs can lead to a misallocation of the corresponding public resources. Consequently, in this context, it is extremely important to analyze the effectiveness/ineffectiveness of such programs.

However, the capacity of public innovation promotion programs to help young companies with high growth capacity not only depends on the bureaucratic framework that the implementation of these programs entails, but also on the structural complexity that political decision making entails, to the extent that three different levels of government coexist in the EU for the promotion of innovation activities: the European level, in charge of innovation projects that generate very large economies of scale and/or externalities that extend beyond the borders of the member states (for example, the existence of large private investment projects in sectors of high technology, which attract special interest from European policy makers, pose an obvious challenge: Who should provide the public funds to stimulate this kind of project: the host country of the private company or the EU? If they are provided by the host country, it would probably lack the funds to finance other smaller projects that are nevertheless of strategic importance to the economy. Therefore, it seems obvious that having exceeded a critical level of economies of scale, the intervention should be made by the European authorities); the national level, responsible for smaller innovation projects that do not generate externalities that can be used by other member states (there are national projects that generate externalities that increase the productivity of companies and institutions from other member countries [4,5]. It is obvious that if the EU does not allocate public resources directly, the project will not be executed, and the joint competitiveness of the European economy will suffer the consequences, because the host country will not be interested in allocating public resources that end up favoring the improvement of other countries' productivity); and the regional level, in control of even smaller innovation projects that are strategic for the economy of the corresponding regions.

On the other hand, in many innovation projects, and in the territorial structure of the EU itself, there are contradictory internal forces that favor or discourage centralized decision making. In this regard, Ederveen et al., Laranja et al., and Oates pointed out some of these internal forces [6-8]: on the one hand, the economies of scale and externalities associated with the spillovers generated by innovation are forces that act in favor of centralization in decision making; on the other hand, differences in tastes, traditions, and the native endowment of resources along with dissimilar structural economic situations are forces that lead to the decentralization and heterogeneity of innovation policy among different member states.

The existence of shared competences among the member states and the EU forces to specify and delimit the spheres of action of the different political levels in decision making. This delimitation is carried out by applying the so-called principle of subsidiarity (the Oxford English Dictionary [9] defines subsidiarity as "the principle that a central authority should have a subsidiary function, performing only those tasks which cannot be performed at a more local level". It also notes that "the Maastricht Treaty reasserts the rights of member nation states through the subsidiarity principle"). This principle recommends that the EU should intervene when the intervention of the member states is insufficient to ensure the achievement of the objectives pursued by the innovation promotion programs. In contrast, the EU should refrain from intervening when the intervention of the member states is enough to achieve these objectives. Obviously, the same principle is also applicable to the distribution of competencies between the various state agencies involved and the relevant regional agencies that exist within the same country.

However, the precise delimitation of the objectives that each of the innovation promotion agencies should pursue is very difficult to implement in the field of decision making, so it is very possible that different agencies manage political strategies, objectives and modes of implementation the underlying rationality of which is not consistent [10], leading to overlaps between them and, consequently, a poor application of the principle of subsidiarity and a possible inefficient allocation of public resources.

In general, Spanish companies have access to different public innovation promotion agencies simultaneously, and so the final impact on the innovation capabilities of these companies may depend 
on the mixes that companies make with the help provided by these agencies, as well as the coherence and consistency of their respective objectives [11].

In this sense, the aim of this study is to shed some light on the possible existence of overlaps between the different innovation promotion agencies operating in the Spanish economy (Framework Programme, European, national, and regional). If the existence of overlapping evidence is inferred from the empirical analysis, this will be a wake-up call for further studies aimed at more precisely unraveling the inconsistencies of the innovation promotion system currently in force in Spain.

To analyze the relationships between different government agencies, we use the adoption approach. This is an econometric strategy that was first used by Arora and Gambardella [12] to analyses the level of interaction between different innovation strategies. Initially, Arora and Gambardella pointed out that if two activities are complementary, the adoption of one activity increases the probability of carrying out the other, so that the corresponding correlation coefficient will be positive and statistically significant [12]. Therefore, these authors proposed the correlation analysis to detect the existence of complementarity between the strategies adopted by the companies. Therefore, this method was called the adoption approach. However, Arora subsequently acknowledges that his method provides indications of complementarity, but not irrefutable evidence of its existence [13]. Complementarity is more than the joint adoption of different strategies. The method proposed by Arora and Gambardella has the advantage of its simplicity, since it is only necessary to know the strategies that coexist within companies for its application. That is why other authors call this method the coexistence approach $[14,15]$. In essence, this method provides indications of the existence of complementarity/substitutability relationships-the veracity of which must be verified by obtaining more comprehensive information and applying complex econometric methods [16-19]. Subsequently, many other studies have used the same econometric technique (e.g., [14-16]).

All in all, through the adoption approach, we will explore whether there are signs of substitution among the public subsidies for innovation granted by the various government agencies of the Spanish area (i.e., whether the fact that an agency grants public aid implies that the other ones tend to reduce their support, and vice versa), signs of complementarity (the agencies act in the same direction; therefore, if some agencies increase their leases, so do the other ones, and vice versa), or, conversely, have no relationship between them (there is no defined pattern regarding their respective joint behavior).

Hereinafter, the structure of this paper is as follows. In Section 2, we present the theoretical framework for the analysis of the main variables that influence the granting of public subsidies for innovation, as well as the hypothesis about the interaction of the different innovation promotion agencies operating in Spain. Section 3 provides the data, variables and the methodological structure of the empirical study, and Section 4 provides the results and their discussion. Finally, in Section 5, we present the conclusions.

\section{Framework of Public Support for Innovation and Hypothesis}

The method proposed by Arora and Gambardella (1990) is based on the calculation and analysis of the correlation coefficients between the policies or strategies adopted. But such a calculation is not made directly with the values of the variables adopted, since there may be unobserved variables that influence the interaction of observed variables (strategies adopted), and the values that reflect the variables adopted do not collect them. This can lead to erroneous correlation coefficients. Therefore, the adoption approach is implemented in two successive stages. In the first stage, a regression is estimated for each variable under analysis, using as regressors the external variables that may influence their adoption. In the second stage, the correlation coefficients between the variables under analysis are calculated, using the residuals extracted from the previously performed regressions.

Therefore, to apply the adoption approach, it is necessary first to define the variables that, according to the literature on innovation, have a material and substantial influence on the probability that different public agencies will allocate resources for the promotion of innovation. According to the neo-classical and neo-Schumpeterian approaches, the projects that should be subsidized are those 
that promise high social returns, but as a result of the existence of market failures (basically, when the costs and risks of $R \& D$ are too high and there is imperfect appropriability of $R \& D$ returns), firms conduct less R\&D than the social optimum. Consequently, the projects that are more likely to receive public funds are those that have the greatest positive impact on social welfare and a high likelihood that private investment in such projects will be less than the socially optimal.

The various agencies that allocate resources to the promotion of innovation face two challenges when they have to grant/deny public aid that is requested. On one hand, they must use selection systems that will lead to subsidizing projects that have a greater positive impact on social welfare and the competitiveness of the companies that receive public aid. On the other, they should keep in mind that the effectiveness of their decisions is being evaluated. The perception that their decisions are being watched can push public agencies to allocate public resources preferentially to companies that have a higher probability of success in their innovation activities, thereby denying public funding to interesting projects that are submitted by companies that do not have a previous proven track record of success in the field of innovation. This would be a suitable selection by risk-averse public agencies [20]. Therefore, most of the studies that have analyzed the issue of public resource allocation to promote innovation have focused on analyzing the business variables that have the greatest influence on the probability of obtaining public support. In this regard, the literature on innovation considers that the experience of engagement in subsidy programs, patent applications, cooperation with other enterprises or institutions, membership in company groups, sectoral technological intensity, expenditure on R\&D, the level of exports, and firm size are key variables that contribute to the generation of a competitive production structure capable of generating high wages and therefore increasing the standard of living of the population. Thus, it is expected that these variables will also influence the likelihood of receiving public support for innovation.

It is normally assumed that previous experience in achieving public support for innovation has a positive influence on obtaining new public subsidies [21]. Furthermore, it is also usual to assume that more patents [20] are more likely to achieve public subsidies for innovation.

Moreover, Hinloopen [22,23] studied how subsidies influence R\&D cooperation. In general, companies cooperate because this mode of acquisition of technological knowledge enables them to internalize the externalities that R\&D spillovers generate, which helps to reduce the uncertainty that underlies all R\&D activity. However, while companies have found in the internalization of externalities sufficient grounds to establish R\&D cooperation agreements, it is clear that the different public agencies increasingly grant public aid to innovation that is conditioned for establishing further R\&D cooperation agreements [23-25]. The goal that public agencies pursue with the granting of this kind of public aid is twofold: firstly, to promote innovative projects with high social returns and low private returns, which would not exist without public aid; and secondly, to promote the dissemination of technological knowledge between firms through cooperation. On this point, Belderbos et al. [26] suggested that the positive and significant impact of public subsidies on cooperation in R\&D comes mainly from the obligation to cooperate imposed by these subsidies.

Belonging to a group of companies provides greater ease of access to sources of financing, both internal and external. Therefore, it seems logical that public innovation promotion agencies are less willing to finance this kind of company [27]. This reluctance is greater when it comes to firms that belong to foreign groups $[28,29]$.

The ability of firms to generate and exploit new ideas technically and commercially depends on their accumulated R\&D experience [30,31]. Consequently, it is expected that the more technologically complex the sectors to which the companies belong are, the higher the likelihood of them participating in innovative projects and therefore the higher the likelihood of them receiving public support for innovation. In this regard, it should be noted that many public agencies grant aid to strongly established and high-technology companies, to the extent that these kinds of companies have a high probability of achieving commercial or technological success in the development of their innovative projects. This is the so-called strategy of promoting national champions [32]. 
On the other hand, it is usual to assume that companies that invest most in R\&D are more likely to achieve public subsidies for innovation [33,34].

In general, most politicians believe that exports help countries' GDP growth [35] and that exporting firms have higher productivity, are larger, and have the capacity to support higher wages than non-exporting firms [36]. On the other hand, studies show that innovation activities and export activities are complementary $[37,38]$, and that the more technologically intensive companies export more than the less technologically intensive companies [39]. Therefore, support for innovation activities indirectly increases the likelihood that firms will undertake exports [35]. Consequently, it is expected that firms with higher export intensity are more likely to receive R\&D subsidies [40].

Finally, note that the relationship between firm size and R\&D subsidy is ambiguous. Some studies have found a negative relationship between the two variables [41,42], whereas most studies have shown the existence of a positive relationship [33,43,44], according to the strategy of supporting national champions. Nevertheless, in the literature, the belief prevails that large companies are more likely to obtain public support for innovation that the different agencies assign.

This study aims to analyze the interaction between public agencies that promote innovation in the Spanish geographical area. And it does so by applying the adoption approach [12]. Specifically, we are interested in applying the adoption approach to explore whether there are indications of complementarity and/or substitutability among innovation promotion agencies.

Most studies on the effectiveness of innovation subsidy policies use individual data from each of the available public funding agencies, which can lead to significant over(under) estimate of additionality, since in reality a large part of the companies receive a mix of subsidies from regional, national and EU sources at the same time [45]. Therefore, knowledge of possible cases of complementarity or substitutability between the different public agencies is of crucial importance for policy makers, since with this greater knowledge they can design innovation promotion policies that are better based on an academic perspective.

Despite the existence of four different levels with jurisdiction within Spain, few studies have analyzed the behavior of the different government agencies in allocating public resources to promote innovation. However, recent literature emphasizes that a key aspect in promoting innovation depends on the interaction or mix of different innovation policies [10,46,47].

In this regard, some studies have determined that the priorities of innovation policy at every level of government are different and therefore every government level allocates public funds to companies with specific characteristics [40,48]. These studies indicate that the determining variables for granting public aid for innovation are not exactly the same at the different government levels analyzed, and that the programs of these different government levels have been designed ex ante to satisfy different objectives. However, these same studies have also found that there are common factors in all the programs of different government levels. Therefore, the relationship between the different agencies is not clear a priori, because in their respective programs, there are variables that lead them to a relationship of complementarity, while others lead them to a relationship of substitution.

In fact, in the real world, decision making is not as orderly and hierarchical as the principle of subsidiarity claims, since the different agencies do not "pursue a single goal or even a coherent and hierarchical set of goals - rather they pursue a broad and ever-changing range of more or less explicit and implicit, final and intermediate goals and objectives, many of which will conflict in the sense that one can only be obtained at the expense or another" [10], (p. 708). Therefore, it may be the case that the rationales, goals, and implementation modes of the different agencies may not be aligned [49], which will result in the same company resorting to the simultaneous use of different agencies. This would be an indication that the subsidiarity principle does not work properly. Consequently, the correlation coefficient between the agencies involved will be positive and significant-that is, the companies will try to obtain the funds that both agencies offer. In these circumstances, the correlation coefficient is indicating the existence of a possible complementarity between the agencies. On the contrary, if the subsidiarity principle works correctly, the objectives and implementation modes of each agency will 
be perfectly defined and differentiated, so that the same company will have difficulties in obtaining financing from two agencies simultaneously. In this case, resorting to one agency implies giving up the other, so the correlation coefficient will be negative and statistically significant. In these latter circumstances, there are indications of substitutability among the analyzed agencies.

Moreover, the Spanish manufacturing sector is formed mainly of small companies [50], with scarce financial resources to undertake costly innovations and with an average level of productivity that is lower than companies in other advanced European countries [51]. In relation to this class of companies, a recent study on the UK economy has found that the subsidy schemes are complementary for small firms [52]. Therefore, in accordance with the literature reviewed, we propose the following hypothesis:

Hypothesis 1. The correlation coefficients between the variables representative of the public aids granted by the different innovation promotion agencies operating in Spain (Regional public funds, National public funds, EU structural public funds and EU Framework Program) are positive and statistically significant. Therefore, there are indications of complementarity between the different agencies.

\section{Data, Variables and Methodology}

\subsection{Data}

The data used in this paper come from the microdata of the Panel de Innovación Tecnológica 2015 y 2016 (PITEC 2015, 2016). This database is produced by the National Statistics Institute of Spain (INE) by following the guidelines set out in the Oslo Manual [53]. The PITEC microdata come from the Community Innovation Survey (CIS). PITEC 2016 collected data on 12,849 companies, and PITEC 2015 collected data on 12,844 companies. The manufacturing sector consists of 3105 companies, while innovative manufacturing encompasses 2547 companies (innovating firms are defined as those that report having introduced product innovations or process innovations or having ongoing innovation activities or having abandoned innovation activities).

\subsection{Variables}

Next, we define the variables that we use in the empirical study. The variables with (t-1) are constructed with data from 2015. The remaining variables are constructed with data from 2016.

\subsubsection{Dependent Variables}

(1) Regional public funds (REGFUND). Its value is 1 if the company receives public funds from Spanish regional agencies for the promotion of innovation. If the company does not receive them, its value is 0 .

(2) National public funds (NATFUND). Its value is 1 if the company receives public funds from the Spanish national agency for the promotion of innovation. If the company does not receive them, its value is 0 .

(3) EU structural public funds (EUFUND). Its value is 1 if the company receives public funds from the European agency for the promotion of innovation. If the company does not receive them, its value is 0 .

(4) EU Framework Programme (FRAFUND). Its value is 1 if the firm receives public funds from the Seventh Framework Programme. If the company does not receive them, its value is 0 .

\subsubsection{Independent Variables}

(1) Experience in subsidy programs (t-1). Its value is 1 if the company has received public funds from one or more programs for the promotion of innovation. If the company does not receive them, its value is 0 . To determine this variable, we do not compute the subsidy program that acts as the dependent variable. 
(2) Patents application ( $\mathrm{t}-1$ ). Its value is 1 if the company applies one or more patents. If the company does not solicit patents, its value is 0 .

(3) Cooperation ( $\mathrm{t}-1$ ). Its value is 1 if the company cooperates with other firms or public institutions. If it does not cooperate, its value is 0 .

(4) Group. Its value is 1 if the company belongs to a group. If it does not belong to a group, its value is 0 .

(5) Sectoral technological intensity. According to the OECD [41], the manufacturing sectors are divided into four classes of technological intensity: low (1), medium-low (2), medium-high (3), and high (4).

(6) RED expenditure ( $\mathrm{t}-1)$. $R \& D$ internal and external expenses in relation to the total sales of the firm.

(7) Exports intensity (t-1). The export share over the total firm sales.

(8) Size. Natural logarithm of the number of employees.

\subsection{Methodology}

It is said that two variables are complementary when the impact of the joint implementation of both variables on the results is greater than the sum of the impact of the implementation of each of these variables separately [54-56].

Thus, this definition of complementarity implies that the marginal performance of each variable increases when the use of the other variables increases. Furthermore, this definition also confirms that if two variables are complementary, the adoption of one of them increases the probability of adopting the other. From this, we can deduce the existence of a clear positive correlation between them. Moreover, the so-called "revealed preference theory" also points out that, in the presence of two complementary activities, the pursuit of maximum efficiency provokes institutions to tend to adopt both activities together or not to take either, which inevitably leads to the existence of a positive correlation between such activities [57]. Therefore, the assumption of complementarity between two variables necessarily entails that the two variables are implemented jointly, so that the correlation coefficient of the two variables is positive and statistically significant.

From the relationship between complementarity and correlation coefficients, Arora and Gambardella [12] proposed the determination of the correlation coefficients of the involved variables as an empirical method to test the complementarity. If the coefficient was positive and statistically significant, Arora and Gambardellla assumed the existence of complementarity between the variables analyzed.

However, subsequently Arora [13] admitted that the existence of positive and significant correlation coefficients does not constitute an irrefutable proof of complementarity, since two variables can coexist without producing synergistic effects on the results. As a result of these considerations, it is currently accepted that the method proposed by Arora and Gambardella [12] is not irrefutable proof of complementarity but provides evidence of complementarity. Therefore, the test proposed by Arora and Gambardella [12] will have three possible interpretations:

(1) If the correlation coefficient is positive and statistically significant, it can be said that there is evidence of complementarity between the analyzed variables, since as one of the variables increases, the other also increases, and vice versa.

(2) If the correlation coefficient is negative and statistically significant, it can be said that there is evidence of substitution between the analyzed variables, since as one of the variables increases, the other decreases, and vice versa.

(3) If the correlation coefficient is not statistically significant, the analyzed variables are independent, i.e., a definite pattern cannot be statistically inferred from the relationship of the analyzed variables.

Below, we briefly expose the basics of the method proposed by Arora and Gambardela [12].

Taking into consideration the existence of variables $\mathrm{V}_{1}$ and $\mathrm{V}_{2}$, let us assume that each variable (activity, resource, strategy, program, etc.) can take the value 0 or the value 1: the first one would 
indicate that the analyzed company has not implemented this variable, and the second one would indicate that this variable has been implemented. The approach of Arora and Gambardella states that when the two variables covary positively, the correlation coefficient is positive, and therefore there will be evidence of complementarity between the two variables. On the contrary, if the covariance is negative for the two variables, the indications will be of substitution.

However, there may be unobserved variables that influence the interaction of variables, and the observed values do not collect them. If this happens, the correlation index calculation using the observed values of the analyzed variables may not accurately reflect the corresponding degree of covariation. As indicated by Athey and Stern [58], these unobserved variables can distort the levels and signs of the correlation coefficients, so the observed values should not be used to calculate these coefficients.

Therefore, in order to achieve consistent correlation coefficients and control the side effects of unobserved variables, Arora and Gambardella [12] proposed introducing into the analysis of the method of adoption a vector of exogenous variables $(Z)$ that influences the decision to adopt the analyzed variables $\left(V_{1}\right.$ and $\left.V_{2}\right)$. The method suggested by these authors is to regress the variables to be analyzed (considered in a non-exclusive mode) on the set of exogenous variables, determine the corresponding regression errors and calculate the covariance of these errors. If the covariance is positive and significant, the existence of indications of complementarity between the analyzed variables is assumed. If the covariance is negative and significant, it is assumed that there are indications of substitution between the analyzed variables. Finally, if the covariance is not significant, it is assumed that the relationship between the variables is independent. Obviously, in the regression analysis, it is assumed that the expected value of the residuals is zero and its variance is equal to unity. From a formal point of view, the analysis model can be presented as follows:

$$
\begin{gathered}
\mathrm{V}_{1}=\alpha_{1} \mathrm{Z}+\epsilon_{1} \\
\mathrm{~V}_{2}=\alpha_{2} \mathrm{Z}+\epsilon_{2} \\
\mathrm{E}\left(\epsilon_{1}\right)=\mathrm{E}\left(\epsilon_{2}\right)=0 \operatorname{Var}\left(\epsilon_{1}\right)=\operatorname{Var}\left(\epsilon_{2}\right)=1
\end{gathered}
$$

If, $\operatorname{Cov}\left(\epsilon_{1}, \epsilon_{2}\right)>0$, Evidence of complementarity between $V_{1}$ and $V_{2}$

If, $\operatorname{Cov}\left(\epsilon_{1}, \epsilon_{2}\right)<0$, Evidence of substitution between $V_{1}$ and $V_{2}$.

Because of its restrictiveness and simplicity, the adoption approach is widely used. One of its main advantages is that it can be practiced from the information available on the adoption of activities by companies or institutions. Thus, the availability of additional information is not necessary (for example, access to a representative measure of performance, as happens with other methods that attempt to evaluate the existence of complementarity).

Following the econometric strategy proposed by Arora and Gambardella [12], we regress each of the dependent variables on the set of independent variables that have some kind of influence on the granting of R\&D subsidies. From these regressions, we extract the corresponding residuals in order to proceed to calculate the correlation coefficients between them.

However, the procedure proposed by Arora and Gambardella [12] requires, in our case, a previous process, because the above regressions are performed with the data of manufacturing firms that innovate, the only ones that could potentially receive public aid for innovation. However, to focus solely on innovative companies, we must take into account the possibility of finding selection bias, because the sample used was not selected at random.

In econometrics, this potential problem has been solved by the so-called Heckman correction [59], applicable when the dependent variable is continuous. When the dependent variable is binary, as in our study, a variant of the Heckman correction method, called the "probit model with simple selection", is often used (Heckprob). This econometric strategy is performed in two stages and uses two equations: 
(a) In the first stage, we use a selection equation. This equation uses the data of all manufacturing companies (3105 companies), whether innovative or not. The dependent variable of the selection equation should consider whether the company is innovative or not (variable selection), while the independent variables are a set of variables that have some kind of influence on the probability of being an innovative company. We included as independent variables identical or similar variables to those used by other studies that have analyzed the probability of being an innovative company. On the other hand, we must bear in mind that to obtain consistent estimators, the independent variables in the equation of interest must be a strict subset of the independent variables of the selection equation [60]. Therefore, the selection equation has the same variables as the equation of interest, plus one or several additional variables. The additional variables we use are the classic obstacles to innovation (cost, financial, knowledge and market), to which literature recognizes an important influence on the probability of innovating. The selection equation is estimated by probit. After the regression, the inverse of the Mills ratio is calculated.

(b) In the second stage, we estimate the so-called equation of interest. This equation is composed of the variables defined in Section 3.2 and the inverse of the Mills ratio, obtained in the probit estimate of the first step. This regression uses only innovative companies (2547 companies). To avoid endogeneity problems, some variables are included with a one-period lag. This second estimate provides the coefficients of the variables of interest duly corrected for the selection bias that might occur. We finally determine the residuals, calculating the difference between observed and estimated values in the equation of interest.

\section{Results and Discussion}

In Table 1, we can see the number of companies that receive public resources from each innovation promotion agency. We found that the Spanish National Agency has granted public funds to 770 companies and the set of regional agencies has granted public funds to 512 companies. The European agency and the Seventh Framework Programme are much more selective, and they finance 226 and 115 companies, respectively.

Table 1. Descriptive statistics.

\begin{tabular}{ccccc}
\hline & \multicolumn{3}{c}{ Innovative Manufacturing Firms } \\
\hline & $\begin{array}{c}\text { Regfund } \\
\mathbf{( 5 1 2 )}\end{array}$ & $\begin{array}{c}\text { Natfund } \\
\mathbf{( 7 7 0 )}\end{array}$ & $\begin{array}{c}\text { Eufund } \\
\mathbf{( 2 2 6 )}\end{array}$ & $\begin{array}{c}\text { Frafund } \\
\mathbf{( 1 1 5 )}\end{array}$ \\
\hline Experience in subsidy programs (t-1) & $281(54.9 \%)$ & $332(43.1 \%)$ & $190(84.1 \%)$ & $108(93.9 \%)$ \\
\hline Patents application (t-1) & $102(19.9 \%)$ & $190(24.7 \%)$ & $71(31.4 \%)$ & $46(40.0 \%)$ \\
\hline Cooperation (t-1) & $318(62.1 \%)$ & $501(65.1 \%)$ & $178(78.8 \%)$ & $98(85.2 \%)$ \\
\hline Group & $289(56.4 \%)$ & $474(61.5 \%)$ & $138(61.1 \%)$ & $74(64.3 \%)$ \\
\hline Sectoral technological intensity (Low) & $107(20.9 \%)$ & $194(25.2 \%)$ & $42(18.6 \%)$ & $17(14.8 \%)$ \\
\hline Sectoral technological intensity & $167(32.6 \%)$ & $178(23.1 \%)$ & $60(26.5 \%)$ & $30(26.1 \%)$ \\
\hline Medium-Low) & $192(37.5 \%)$ & $300(39.0 \%)$ & $97(42.9 \%)$ & $49(42.6 \%)$ \\
\hline Sectoral technological intensity & & & $19(16.5 \%)$ \\
\hline (Medium-High) & $46(9.0 \%)$ & $98(12.7 \%)$ & $27(11.9 \%)$ \\
\hline Sectoral technological intensity (High) & $0.0452(0.1147)$ & $0.0461(0.1137)$ & $0.0711(0.1927)$ & $0.0750(0.1996)$ \\
\hline R\&D expenditure (t-1) & $0.4670(0.3268)$ & $0.4425(0.3239)$ & $0.4524(0.3283)$ & $0.4987(0.3235)$ \\
\hline Size & $2.0072(0.5848)$ & $2.0765(0.5594)$ & $2.1230(0.6245)$ & $2.1902(0.6706)$ \\
\hline
\end{tabular}

Number $(\%)=$ Number of companies (percentage over the total firms which receive public funding). Number (Number) = Mean (Standar deviation). Regional public funds (REGFUND). National public funds (NATFUND). EU structural public funds (EUFUND). EU Framework Programme (FRAFUND).

Of the companies that have achieved public funding from the Framework Programme, 93.9\% have experience in subsidy programs. In the European agency, this percentage is $84.1 \%$. In the set of regional agencies, only $43.1 \%$ have experience in subsidy programs. 
In relation to the patent application, we found that the percentage of firms that receive public funds and apply for patents is much higher in the set of companies that receive public funding from the Framework Programme (40.0\%) and the European agency $(31.4 \%)$ than those receiving public funding from the Spanish National Agency (24.7\%) or the set of regional agencies (19.9\%).

On R\&D cooperation, we found that the percentage of firms that receive public funds and cooperate with other companies is much higher in the set of companies that receive public funding from the Framework Programme (85.2\%) and the European agency (78.8\%). These data provide an indication that the allocation of public resources to innovation by the European authorities follows the requirement of greater conditionality towards cooperation with other enterprises or institutions.

Membership in a group of companies does not seem to grant an advantage to obtain public financing from any of the four agencies analyzed, since the percentage of companies that belong to a group is quite similar among the companies that receive financing from the four agencies. The highest percentage is for the Framework Programme (64.3\%) and the lowest is for the set of regional agencies $(56.4 \%)$.

Regarding the technological intensity, we found that all the agencies pay special attention to the companies belonging to medium-high technological intensity sectors. In percentage terms, with the exception of the Framework Programme, the companies belonging to high technological intensity sectors receive the least attention, followed by those belonging to low or medium-low technological intensity sectors. It is obvious that the government tries to make safe bets with its resources, an issue that guarantees a higher probability of success in their respective assignments. Therefore, the companies belonging to the low technological intensity sectors and high technological intensity sectors (in this case, the technical and commercial uncertainties of the projects are very high) receive proportionately fewer public resources.

Moreover, we find that, on average, the Framework Programme (0.0750) and the European agency (0.0711) tend to grant subsidies to innovative companies that perform higher R\&D expenses.

In addition, we found that the exports intensity of the subsidized firms by the four agencies analyzed is virtually the same, with a slight selective bias towards exporting companies by the Framework Program (0.4987).

Finally, we found that the average size of firms receiving public support for innovation is greater the more distant the agency that allocates resources is. Thus, we could see that the average size of the companies subsidized by regional agencies is 2.0072, while it is 2.1902 in the Framework Programme.

Table 2 shows the results of the four regressions made with the equation of interest, in which the dependent variables are, respectively, regional agency, national agency, European agency and Framework Programme. Since the objective of this study is not to analyses the determinants of the likelihood of granting public support for innovation by each of the different public agencies, we will not extrapolate conclusions on the coefficients of the variables of interest. In this study, we are only interested in the residuals generated by these regressions, since they allow us to determine evidence of complementarity/substitution among the four agencies analyzed, which is the main objective of this study.

Finally, Table 3 shows the correlation coefficients between the residuals of the equations of interest.

There are six non-trivial peer relationships that can be established between the four agencies analyzed. In Table 3, it can be seen that, of these six relationships, five exhibit a positive and statistically significant correlation coefficient. Only the relationship between the Spanish national agency and the set of regional agencies has a negative correlation coefficient, although not statistically significant. Therefore, there are indications of substitution in the relations between these two agencies, although from the statistical perspective these relations are not significant. In this case, there are weak indications that the Spanish agency and the corresponding regional agencies pursue a hierarchical set of objectives, mediated by the principle of subsidiarity, so that companies have a difficult time resorting to the financing of both agencies simultaneously. Therefore, in this case, there are indications, not statistically proven, that the principle of subsidiarity works correctly. 
However, the remaining relationships between different agencies result in positive and statistically significant correlation coefficients. This is a clear indication that companies turn to financing offered by the different agencies at the same time, which means that the agencies complement each other, so the implementation of the subsidiarity principle does not seem to work properly in these cases. Therefore, it should be stressed that the hypothesis raised is not met in strict terms, but in most of the relationships between agencies.

A possible explanation of the evidence that the principle of subsidiarity seems to work better between Spanish agencies than between these and the two European agencies involves the different legal framework that mediates political decision making in each case. In this regard, the legal framework between the Spanish central power and its different regional governments is much better defined than that which mediates the relationship between Spain and the EU. Spain is a political unit, and the EU is not.

Table 2. Results of the regression of the equations of interest.

\begin{tabular}{ccccc}
\hline & Regfund & Natfund & Eufund & Frafund \\
\hline Experience in subsidy programs (t-1) & $0.4956^{* * *}$ & $0.4681^{* * *}$ & $0.8273^{* * *}$ & $\begin{array}{c}1.1577^{* * *} \\
\end{array}$ \\
& $(0.0650)$ & $(0.0629)$ & $(0.0939)$ & $(0.1737)$ \\
\hline Patents application (t-1) & 0.0590 & $0.4064^{* * *}$ & $0.3027^{* * *}$ & $0.3970^{* * *}$ \\
& $(0.0831)$ & $(0.0777)$ & $(0.0978)$ & $(0.1174)$ \\
\hline Cooperation (t-1) & $0.3840^{* * *}$ & $0.5329^{* * *}$ & $0.5709^{* * *}$ & $0.5990^{* * *}$ \\
& $(0.0655)$ & $(0.0599)$ & $(0.0916)$ & $(0.1309)$ \\
\hline Group & $-0.1375^{*}$ & -0.0728 & $-0.1815^{*}$ & -0.1682 \\
& $(0.0715)$ & $(0.0663)$ & $(0.0971)$ & $(0.1279)$ \\
\hline Sectoral technological intensity (Medium-Low) & $0.3587^{* * *}$ & -0.1188 & 0.1734 & 0.2079 \\
& $(0.0829)$ & $(0.0788)$ & $(0.1152)$ & $(0.1596)$ \\
\hline Sectoral technological intensity (Medium-High) & 0.0699 & -0.0525 & 0.1658 & 0.1870 \\
& $(0.0791)$ & $(0.0716)$ & $(0.1078)$ & $(0.1495)$ \\
\hline Sectoral technological intensity (High) & -0.1059 & 0.0484 & 0.0543 & 0.3011 \\
& $(0.1127)$ & $(0.1001)$ & $(0.1463)$ & $(0.1841)$ \\
\hline R\&D expenditure (t-1) & 0.2103 & $0.3157^{*}$ & $0.5865^{* * *}$ & $0.4541^{*}$ \\
& $(0.1973)$ & $(0.1891)$ & $(0.1915)$ & $(0.2494)$ \\
\hline Exports intensity (t-1) & $0.3036^{* * *}$ & 0.1114 & -0.0378 & 0.1500 \\
& $(0.0935)$ & $(0.0873)$ & $(0.1262)$ & $(0.1660)$ \\
\hline Size & 0.0705 & $0.2913 * * *$ & $0.2716^{* * *}$ & $0.2880^{* * *}$ \\
& $(0.0651)$ & $(0.0604)$ & $(0.0844)$ & $(0.1083)$ \\
\hline Constant & $-1.5220^{* * *}$ & $-1.4684^{* * *}$ & $-2.8034^{* * *}$ & $-3.7331^{* * *}$ \\
& $(0.1329)$ & $(0.1242)$ & $(0.2129)$ & $(0.2901)$ \\
\hline
\end{tabular}

Statistical significance of the coefficients: $1 \%{ }^{* * *}, 5 \%$ ** and $10 \% *$.

With the previous results, we have verified that almost all the correlation coefficients of the relations between the four innovation promotion agencies analyzed are positive and statistically significant. This means that companies receive public funding from different agencies at the same time $[29,61]$. And if they do so, it is because companies expect to earn more than using a single source of financing. In this sense, it should be stressed that we only know two studies that analyze the contribution of the mix of innovation promotion agencies. On the one hand, a study by Czarnitzki and Lopes Bento has found that the simultaneous use of European funding and national funding stimulates higher sales of market novelties and future patent applications at the firm level [29]. On the other hand, the study carried out by Mulligan, Lenihan and Doran has also found that resorting at the same time to the financing offered by regional, national and EU agencies leads to levels and forms of innovation with greater private or social returns [45]. However, both studies do not allow confirmation that there is complementarity between the different agencies that they analyze, since the econometric method used in these studies was not the complementarity approach (see, for example, $[16,62,63])$, and so their results only provide evidence of complementarity. 
However, although the complementarity approach has not yet been used to analyze the mix of innovation promotion agencies, it has been used to analyze mixtures of the financing instruments that these agencies use (R\&D subsidy and R\&D tax credit, mainly). Thus, a study by Pless has found that the mix of R\&D subsidy and R\&D tax credit is complementary for small businesses in the UK [52]. This finding is in line with the results that the adoption approach provides in our study, since most Spanish companies are also Small Medium Enterprises (SMEs). Likewise, a study by Mulligan, Lenihan and Doran has found that receiving a combination of two different innovation policy instruments has complementary effects on firm-level innovation [49].

Table 3. Correlation coefficients between the residuals of the equations of interest.

\begin{tabular}{ccccc}
\hline & Regfund & Natfund & Eufund & Frafund \\
\hline Regfund & 1 & & & \\
Natfund & -0.0123 & 1 & 1 & \\
Eufund & $0.1277^{* * *}$ & $0.0715^{* * *}$ & $0.6444^{* * *}$ & 1 \\
Frafund & $0.1185^{* * *}$ & $0.0408^{* *}$ & $\%^{* *}$ and $10 \%$.
\end{tabular}

As a summary, the results of our study are in line with the few previous studies that have addressed the simultaneous use of different innovation promotion agencies. Our main contribution is that we make them from the adoption approach, which has never been previously used in this kind of study. Therefore, it constitutes a new analytical perspective in this kind of study as well as a warning on the need to continue deepening the investigation into the interaction of the different agencies, since the few studies on this subject are consistent in pointing out that companies that receive a mix of subsidies from regional, national and EU sources achieve various kinds of benefits in the field of innovation. Likewise, society as a whole also benefits through the corresponding spillovers that these companies generate [45,64].

\section{Conclusions}

Most studies on public innovation promotion programs assess the impact of subsidies on companies by taking each source of public funding separately. However, a large number of companies receive public funding from different agencies at the same time, so the interaction between these agencies can alter the results of innovation that companies get. Ignoring this reality in studies can lead to an over- or under-estimation of additionality $[29,45,61]$. However, the empirical research on the relationship between different innovation promotion agencies remains scarce.

In this sense, our paper contributes to extending the empirical investigation on this question, using the adoption approach as an important research tool. This paper explores the interaction between the four kinds of agency for innovation support operating in Spain (Framework Programme, European, national, and regional), in order to determine whether there are indications of complementarity/substitutability between these four agencies. The adoption approach uses correlation coefficients between different agencies to detect these clues. So, if companies use financing provided by different agencies at the same time, the correlation coefficient between the analyzed agencies will be positive, since obtaining financing from one agency does not mean giving up obtaining financing from others. In this case, there are indications that the different agencies complement each other. On the contrary, if the objectives pursued and the design of the financing granting processes of the different agencies are mutually exclusive, obtaining financing from one agency would mean giving up the financing of other agencies. In this case, the agencies would tend to replace each other, and the corresponding correlation coefficient would be negative. If so, it is said that there are indications of substitution.

The results of our analysis show indications of complementarity in most of the relationships between the four agencies analyzed. Only the relationship between the Spanish national agency and 
the set of regional agencies exhibits signs of substitution. These results constitute an indicator that the exact design of the objectives and selection processes of these two agencies have been made under the guidelines of the so-called subsidiarity principle. However, the coordination between the two Spanish agencies and the two European agencies is much more diffuse, probably due to a poor implementation of the subsidiarity principle. It must be taken into account that the framework in which political decisions are made is more clearly defined in Spain than in the EU: in Spain, there is a political unit, while in the EU it does not yet exist.

These findings may be an important guide in the decision making of managers, to the extent that they provide information on how other companies are acting in the search for public financing for their innovation projects. Knowing which agencies are mutually exclusive and which are complementary is extremely relevant information, mainly for small businesses that have limited capacities and resources to analyze the most advantageous financing strategies. In addition, they can be useful to policy makers in their task of designing innovation promotion policies. The policy makers have to be continually evaluating whether the innovation promotion programs implemented reach the proposed objectives, and whether there are other more efficient alternative policies. Therefore, knowing that companies tend to use a mix of subsidies, and that different subsidy programs interact with each other, highlights the importance of knowing the mechanisms of this mutual interaction.

Finally, we recognize that our paper is not without its limitations, some of which are opportunities for new studies. Companies not only receive public funding from different agencies, but this mix of financing changes over time [46]. In addition, it must also be taken into account that, from a temporary perspective, not only do some agencies interact with each other, but there is also interaction between the aid received from the same agency in different and successive stages [65]. Therefore, it would be desirable for future research to use panel data instead of cross-sectional data. The use of panel data allows a deeper analysis of the interactions that take place between the different agencies. In addition, it facilitates the overcoming of the problems caused by the unobservable heterogeneity present mainly in the cross-sectional data [66].

Author Contributions: J.G.-B., M.V.-A., and M.G.-G. All authors contributed equally to this work; all authors wrote, reviewed and commented on the manuscript; all authors have read and approved the final manuscript.

Funding: This research received no external funding.

Conflicts of Interest: The authors declare no conflict of interest.

\section{References}

1. McKelvie, A.; Wiklund, J. Advancing firm growth research: A focus on growth mode instead of growth rate. Entrep. Theory Pract. 2010, 34, 261-288. [CrossRef]

2. UNCTAD. Science, Technology \& Innovation Capacity Development Course. Module 3. Fostering Innovation. Available online: https://unctad.org/en/PublicationsLibrary/dtlstictinf2019d2_en.pdf (accessed on 11 October 2019).

3. Djankov, S.; La Porta, R.; Lopez-de-Silanes, F.; Shleifer, A. The Regulation of Entry. Q. J. Econ. 2002, 117, 1-37. [CrossRef]

4. Capron, H.; Cincera, M. Exploring the spillover impact on productivity of worldwide manufacturing firms. In The Economics and Econometrics of Innovation; Encaoua, D., Hall, B.H., Laisney, F., Mairesse, J., Eds.; Kluwer Academic Publishers: Boston, MA, USA, 2000; pp. 543-566.

5. Keller, W. International technology diffusion. J. Econ. Lit. 2004, 42, 752-782. [CrossRef]

6. Ederveen, S.; Gelauff, G.; Pelkmans, J. Assessing subsidiarity. In Subsidiarity and Economic Reform in Europe; Gelauff, G., Grilo, I., Lejour, A., Eds.; Springer: Heidelberg, Germany, 2008; pp. 19-40.

7. Laranja, M.; Uyarra, E.; Flanagan, K. Polices for science, technology and innovation: Translating rationales into regional policies in a multi-level setting. Res. Policy 2008, 37, 823-835. [CrossRef]

8. Oates, W.E. The Economics of Fiscal Federalism and Local Finance; Edward Elgar: Cheltenham, UK, 1998.

9. Oxford English Dictionary. Available online: https://en.oxforddictionaries.com/definition/subsidiarity (accessed on 10 October 2019). 
10. Flanagan, K.; Uyarra, E.; Laranja, M. Reconceptualising the 'policy mix' for innovation. Res. Policy 2011, 40, 702-713. [CrossRef]

11. Martin, B.R. R\&D policy instruments-A critical review of what we do and don't know. Ind. Innov. 2016, 23, 157-176.

12. Arora, A.; Gambardella, A. Complementarity and external linkages: The strategies of the large firms in biotechnology. J. Indust. Econ. 1990, 38, 361-379. [CrossRef]

13. Arora, A. Testing for complementarities in reduced-form regressions: A note. Econ. Lett. 1996, 50, 51-55. [CrossRef]

14. Vega Jurado, J.M.; Gutiérrez-Gracia, A.; Fernández-de-Lucio, I. La relación entre las estrategias de innovación: Coexistencia o complementariedad. J. Technol. Manag. Innov. 2009, 4, 74-88. [CrossRef]

15. Guisado-González, M.; Guisado-Tato, M.; Sandoval-Pérez, A. Technological determinants of innovation performance in Spanish hospitality companies: An analysis of the coexistence of innovation strategies. Serv. Ind. J. 2013, 33, 580-593. [CrossRef]

16. Cassiman, B.; Veugelers, R. In search of complementarity in innovation strategy: Internal R\&D and external knowledge acquisition. Manag. Sci. 2006, 52, 68-82.

17. Guisado-González, M.; Wright, L.T.; Guisado-Tato, M. Product-process matrix and complementarity approach. J. Technol. Transf. 2017, 42, 441-459. [CrossRef]

18. González-Blanco, J.; Vila-Alonso, M.; Guisado-González, M. Exploring the complementarity between foreign technology, embedded technology and increase of productive capacity. Tech. Econ. Dev. Econ. 2019, 25, 39-58. [CrossRef]

19. Ballot, G.; Fakhfakh, F.; Galia, F.; Salter, A. The fateful triangle. Complementarities between product, process and organizational innovation in the UK and France. Res. Policy 2015, 44, 217-232. [CrossRef]

20. Huergo, E.; Trenado, M. The application for and the awarding of low-interest credits to finance R\&D projects. Rev. Ind. Organ. 2010, 37, 237-259.

21. Huergo, E.; Trenado, M.; Ubierna, A. Impact of Low-Interest Credits on Business RED Expenditures: Spanish Firms and CDTI Loans for RED Projects. MPRA Paper No. 44221. 2013. Available online: https://mpra.ub.unimuenchen.de/44221/2/MPRA_paper_44221.pdf (accessed on 7 September 2019).

22. Hinloopen, J. Subsidizing cooperative and noncooperative R\&D in duopoly with spillovers. J. Econ. 1997, 66, 151-175.

23. Hinloopen, J. More on subsidizing cooperative and noncooperative R\&D in duopoly with spillovers. J. Econ. 2000, 72, 295-308.

24. Acosta, J.; Modrego, A. Public financing of cooperative R\&D projects in Spain: The concerted projects under the national R\&D plan. Res. Policy 2001, 30, 625-641.

25. Abramovsky, L.; Kremp, E.; López, A.; Schmidt, T.; Simpson, H. Understanding co-operative innovative activity: Evidence from four European countries. Econ. Innov. New Technol. 2009, 18, 243-265. [CrossRef]

26. Belderbos, R.; Carree, M.; Diederen, B.; Lokshin, B.; Veugelers, R. Heterogeneity in R\&D cooperation strategies. Int. J. Ind. Organ. 2004, 22, 1237-1263.

27. Huergo, E.; Moreno, L. National or International Public Funding? Subsidies or Loans? Evaluating the Innovation Impact of R\&D Support Programmes. MPRA Paper No. 64926. 2014. Available online: https:/pdfs.semanticscholar.org/80da/9d17efca7d413a69d3d68488f511eda41088.pdf?_ga=2. 197749161.760267254.1571248616-1898024344.1567876812 (accessed on 8 August 2019).

28. García, A.; Mohnen, P. Impact of Government Support on R\&D and Innovation. In UNU-MERIT Working Paper Series 2010-034; United Nations University, Maastricht Economic and Social Research and Training Centre on Innovation and Technology: Maastricht, The Netherlands, 2010.

29. Czarnitzki, D.; Lopes-Bento, C. Innovation subsidies: Does the funding source matter for innovation intensity and performance? Empirical evidence from Germany. Ind. Innov. 2014, 21, 380-409. [CrossRef]

30. Cohen, W.M.; Levinthal, D.A. Innovation and learning: The two faces of R\&D. Econ. J. 1989, 99, 569-596.

31. Cohen, W.M.; Levinthal, D.A. Absorptive capacity: A new perspective on learning and innovation. Adm. Sci. Q. 1990, 35, 128-152. [CrossRef]

32. Blanes, J.V.; Busom, I. Who participates in R\&D subsidy programs? The case of Spanish manufacturing firms. Res. Policy 2004, 33, 1459-1476.

33. Wallsten, S. The effects of government-industry R\&D programs on private R\&D: The case of the small business innovation research program. RAND J. Econ. 2000, 31, 82-100. 
34. Huergo, E.; Trenado, M.; Ubierna, A. The impact of public support on firm propensity to engage in R\&D: Spanish experience. Technol. Forecast. Soc. Chang. 2016, 113, 206-219.

35. Sissoko, A. RED Subsidies and Firm-Level Productivity: Evidence from France; Discussion Paper 2011-2; Institut de Recherches Économiques et Sociales de l'Université Catholique de Louvain: Belgium, 2013; Available online: https://sites.uclouvain.be/econ/DP/IRES/2011002.pdf (accessed on 17 August 2019).

36. 36- Bernard, A.B.; Jensen, B.J. Exceptional exporter performance: Cause, effect, or both? J. Int. Econ. 1999, 47, 1-25. [CrossRef]

37. Lileeva, A.; Trefler, D. Improved access to foreign markets raises plant-level productivity... For some plants. Q. J. Econ. 2010, 125, 1051-1099. [CrossRef]

38. Aw, B.Y.; Roberts, M.J.; Xu, D.Y. R\&D investment, exporting, and productivity dynamics. Am. Econ. Rev. 2011, 101, 1312-1344.

39. Gemunden, H.G. Success factors of export marketing: A meta-analytic critique of empirical studies. In New Perspectives on International Marketing; Paliwoda, S.J., Ed.; Routledge: London, UK, 1991; pp. 33-62.

40. Guisado-González, M.; Guisado-Tato, M.; Vila-Alonso, M. Using public aid programs to finance innovation in multi-level governance systems. Transylv. Rev. Adm. Sci. 2013, 38, 61-78.

41. Busom, I. An empirical evaluation of the effects of R\&D subsidies. Econ. Innov. New Technol. 2000, 9, 111-148.

42. Lööf, H.; Heshmati, A. The Impact of Public Funding on Private RED Investment: New Evidence from a Firm Level Innovation Study; CESIS Working Paper 06. Sweden, 2005. Available online: http://www.diva-portal.org/ smash/get/diva2:487582/FULLTEXT01.pdf (accessed on 3 August 2019).

43. Almus, M.; Czarnitzki, D. The effects of public R\&D subsidies on firms' innovation activities. J. Bus. Econ. Stat. 2003, 21, 226-236.

44. Hussinger, K. R\&D and subsidies at the firm level: An application of parametric and semi-parametric two-step selection models. J. Appl. Econom. 2008, 23, 729-747.

45. Mulligan, K.; Lenihan, H.; Doran, J. More subsidies, more innovation? Evaluating whether a mix of subsidies from regional, national and EU sources crowds out firm-level innovation. Reg. Stud. Reg. Sci. 2019, 6, 130-138. [CrossRef]

46. Cunningham, P.; Edler, J.; Flanagan, K.; Larédo, P. The innovation policy mix. In Handbook of Innovation Policy Impac; Edler, J., Cunningham, P., Gök, A., Shapira, P., Eds.; Edward Elgar Publishing: Cheltenham, UK, 2016; pp. 505-542.

47. Flanagan, K.; Uyarra, E. Four dangers in innovation policy studies-And how to avoid them. Ind. Innov. 2016, 23, 177-188. [CrossRef]

48. Altuzarra, A. Public funding for innovation at different levels of government: An analysis of Spanish manufacturing. Eur. J. Econ. Financ. Adm. Sci. 2010, 20, 94-105.

49. Mulligan, K.; Lenihan, H.; Doran, J. Are Different Innovation Policy Instruments Complements or Substitutes? A Microeconometric Evaluation Using Panel Data. In Proceedings of the 31st Annual Irish Economic Association Conference, Institute of Banking, Dublin, Ireland, 4-5 May 2017; Available online: https://iea2017.exordo.com/files/papers/123/final_draft/IEA_Conference_2017_Mulligan_Lenihan_ Doran_FINAL.pdf (accessed on 4 June 2019).

50. Huerta Arribas, E.; García Olaverri, C.; Garcés Galdeano, L. El tamaño de las empresas y la calidad del. recurso empresarial: ¿Causa o efecto? Ekonomiaz 2016, 90, 32-55.

51. Roxburgh, C.; Labaye, E.; Thompson, F.; Tacke, T.; Kauffman, D. Investing in Growth: Europe's Next Challenge. McKinsey Global Institute, 2012. Available online: https://www.mckinsey.com/ \{\}/.media/ McKinsey/Featured\%20Insights/Europe/Investing\%20in\%20growth/MGI_Europe_Investing_.Executive_ Summary_Dec2012.ashx (accessed on 20 August 2019).

52. Pless, J. Are "Complementary Policies" Substitutes? Evidence from R\&D Subsidies in the UK. Available online: https://ssrn.com/abstract=3379256 (accessed on 29 July 2019).

53. OECD \& Eurostat. Oslo Manual_Proposed Guidelines for Collecting and Interpreting Technological Innovation Data; OECD \& Eurostat: Paris, France, 1997.

54. Milgrom, P.; Roberts, J. The economics of modern manufacturing: Technology, strategy, and organization. Am. Econ. Rev. 1990, 80, 511-528.

55. González-Blanco, J.; Coca-Pérez, J.L.; Guisado-González, M. Relations between technological and non-technological innovations in the service sector. Serv. Ind. J. 2019, 39, 134-153. [CrossRef] 
56. Guisado-González, M.; González-Blanco, J.; Coca-Pérez, J.L. Exploration, exploitation, and firm age in alliance portfolios. Eurasian Bus. Rev. 2019. [CrossRef]

57. Schmiedeberg, C. Complementarities of innovation activities: An empirical analisis of the German manufacturing sector. Res. Policy 2008, 37, 1492-1503. [CrossRef]

58. Athey, S.; Stern, S. An Empirical Framework for Testing Theories About Complementarity in Organizational Design; NBER Working Paper No. 6600. Cambridge, MA, USA, 1998. Available online: https://www.nber.org/papers/ w6600.pdf (accessed on 27 July 2019).

59. Heckman, J. Sample selection bias as a specification error. Econometrica 1979, 47, 153-161. [CrossRef]

60. Wooldridge, J.M. Selection corrections for panel data models under conditional mean independence assumptions. J. Econom. 1995, 68, 115-132. [CrossRef]

61. Guerzoni, M.; Raiteri, E. Demand-side vs. supply-side technology policies: Hidden treatment and new empirical evidence on the policy mix. Res. Policy 2015, 44, 726-747. [CrossRef]

62. Guisado-González, M.; González-Blanco, J.; Coca-Pérez, J.L.; Guisado-Tato, M. Assessing the relationship between R\&D subsidy, R\&D cooperation and absorptive capacity: An investigation on the manufacturing Spanish case. J. Technol. Transf. 2018, 43, 1647-1666.

63. Guisado-González, M.; González-Blanco, J.; Coca-Pérez, J.L. Analyzing the relationship between exploration, exploitation and organizational innovation. J. Knowl. Manag. 2017, 21, 1142-1162. [CrossRef]

64. Beck, M.; Lopes-Bento, C.; Schenker-Wicki, A. Radical or incremental: Where does R\&D policy hit? Res. Policy 2016, 45, 869-883.

65. Rogge, K.S.; Reichardt, K. Policy mixes for sustainability transitions: An extended concept and framework for analysis. Res. Policy 2016, 45, 1620-1635. [CrossRef]

66. Miravete, E.; Pernias, J. Innovation complementarity and scale of production. J. Ind. Econ. 2006, 54, 1-29. [CrossRef]

(C) 2019 by the authors. Licensee MDPI, Basel, Switzerland. This article is an open access article distributed under the terms and conditions of the Creative Commons Attribution (CC BY) license (http://creativecommons.org/licenses/by/4.0/). 